\title{
U.S. students do not know as much as foreign students about the world
}

\author{
LAWRENCE WEINSTEIN \\ Marymount College of Kansas, Salina, Kansas \\ and \\ ANTON de MAN \\ Bishop's University, Lennoxville, Quebec, Canada
}

\begin{abstract}
Sixteen students randomly selected from a group of foreign students studying in the United States were significantly less ignorant of names and locations of the countries of the world than were randomly chosen matched students who were born, raised, and studying in the United States. Further empirical studies are needed to more adequately investigate this phenomenon.
\end{abstract}

During the past few years, several reports have appeared in the media concerning the apparent failure of the American educational system at the secondary level. Cases have been reported of students who graduated from high school even though they were seriously lacking in their abilities to read and write. At the postsecondary level, universities feel obliged to institute remedial programs in an effort to bring incoming students up to the minimum level of literacy expected from undergraduates.

If the failure to instill the basic skills is indicative of the quality of secondary education, it may be speculated that students also lack in other areas. Therefore, the present study involved a preliminary attempt at answering the question of how knowledgeable of current world geography of U.S. students (students born and raised in the United States, and presently attending colleges or universities in that country) are relative to foreign students (students born and raised in a country other than the U.S. and presently attending colleges or universities in the U.S.

The reason for selecting geography as the area of interest is that many individuals presently receiving higher education may become business, social, and political leaders in the future. Because the U.S. is a world-leading nation, many of the decisions made by its representatives have far-reaching consequences for other countries. It is, therefore, suggested that knowledge of other nations is a necessity. Ideally, leaders are well versed in cultural, economic, and political geography. They should at least know where the various countries are located. It is speculated that many undergraduates are lacking in this knowledge. Therefore, the present study attempted a preliminary examination of U.S. students' knowledge of world geography relative to that of foreign students who are presently studying in the U.S.

Requests for reprints should be sent to L. Weinstein, Marymount College of Kansas, P.O. Box 5050, Salina, KS 67401.

\section{METHOD}

\section{Subjects}

Foreign students were 16 males from Ethiopia, Nigeria, and India. U.S. students were 16 males normally residing in Florida, South Dakota, New York, or Pennsylvania.

Initially, 30 foreign and 50 U.S. students were randomly selected from two colleges in South Dakota. To control some possible causes of difference in knowledge of world geography, potential subjects were matched for age (18-23 years), year in college (2nd), subject studied (psychology or health sciences), and grade point average (3-3.5, where 4 is A). Twenty-one foreign and 26 U.S. students were selected according to these matching criteria. Of these, 16 foreign and 16 U.S. students were randomly chosen.

\section{Materials}

Subjects were provided with a 4-page booklet, the first page of which depicted a map of the world with 132 countries. In lieu of the names of the nations were numbers from 1 to 132 . The remaining pages contained an alphabetical list of the names of the countries with a blank next to each name on which subjects were to record the corresponding numbers taken from page 1 .

\section{Procedure}

Subjects were tested en masse. Instructions read as follows:

This is a study to determine how much people know of world geography and current events around the world. You do not have to participate, but it would be appreciated if you would. You do not have to put your name on this sheet (you will remain anonymous). Your results will be compared with the results from people in other countries. As soon as all the data are collected, you will be informed of the overall findings. Please, enter as many countries' numbers as you are able to. The more numbers you know (and enter on the sheets), the better. Are there any questions? Ready? Begin.

Subjects were then given $2 \mathrm{~h}$ to complete the task.

\section{RESULTS AND DISCUSSION}

The average number of correct responses for the foreign and U.S. students were 12.2 and 5.7, respectively, out of a possible total of 132 . An analysis of variance yielded a significant result $[F(1,30)=7.89, p<.01]$.

The finding of this preliminary study suggested that for- 
eign students knew significantly more about the geography of the world than did their U.S. counterparts.

Students of both groups were attending university in the U.S. They were matched for age, year in college, subject area, and academic performance. They differed as to where they had received their preuniversity education. The question remains, however, whether this constituted the only difference between the two groups. Could it be, for example, that the foreign students represented the educational elite of their respective countries and thus were not a representative sample of university students in their home countries?
Because of questions of this nature, a more involved investigation is called for. A better way to examine foreign and U.S. students' knowledge of geography would be to randomly sample U.S. and foreign students each in their own countries. This method would eliminate the possibility that foreign students presently studying in the U.S. do not constitute a sample representative of students in their home countries.

(Manuscript received for publication November 12, 1986.) 